\title{
The ribosomal RNA (rrn) operons of fast- growing mycobacteria: primary and secondary structures and their relation to rrn operons of pathogenic slow-growers
}

\author{
Yuan-en $\mathrm{Ji}^{1}{ }^{\top}+\mathrm{M}$. Joseph Colston ${ }^{2}$ and Robert A. Cox ${ }^{1}$ \\ Author for correspondence: Robert A. Cox. Tel: +44 81959 3666. Fax: +44 819064477.
}

Laboratory of

Developmental

Biochemistry, ${ }^{1}$ and Leprosy and Mycobacterial

Research, 2 National Institute for Medical Research, The Ridgeway, Mill Hill, London NW7 1AA, UK
The two ribosomal RNA (rrn) operons ( $r$ rnA and $r r n B$ ) of Mycobacterium smegmatis were investigated. The leader regions, part of the 165 rRNA genes, the spacer-1 regions, part of the 235 rRNA genes, and the spacer-2 regions were amplified by PCR or by inverse PCR and the products were cloned and sequenced. No differences in the sequences of the two operons were detected downstream from the Box $A$ antitermination element of the leader region. Upstream from Box A a slow-grower-like Box B antitermination element was found in rrnA but not in rrnB. Primer extension experiments revealed that the start of transcription lies at least 370 nucleotides upstream from the 5'-end of the 165 rRNA gene and an RNase processing site near to the Box $A$ element. Secondary structures were deduced for pre-16S rRNA and pre-235 rRNA which are distinct from, but closely related to, the corresponding structures of slowgrowing mycobacteria. On the basis of these results it is proposed that the emergence of the slow-growers from the main mycobacterial line was coincident with the deletion of a segment of DNA spanning an rrnB-like operon, leaving an rrnA-like operon as the sole source of rRNA. An explanation is also proposed for the need for two Box A motifs in the transcription of an rrn operon based on competition between the polymerase and the nascent 305 subunit for either protein $\mathrm{S} 10$ and/or Box A sequences.

Keywords: fast-growing mycobacteria, slow-growing mycobacteria, precursor rRNA, Box A antitermination, rRNA processing

\section{INTRODUCTION}

Mycobacteria are Gram-positive, acid-fast bacteria. Members of the genus are conveniently classified as either slow-growers or fast-growers. These two groups are phylogenetically distinct although they are closely related (Stahl \& Urbance, 1990; Rogall et al., 1990; Pitulle et al., 1992) based on the sequence of their ribosomal RNA. The pathogenic mycobacteria (mainly Mycobacterium tuberculosis and Mycobacterium leprae, but also including a number of species which are pathogenic to animals) are slowgrowers, and it is thought that slow growth is an important attribute of their pathogenicity.

\footnotetext{
† Present address: Seattle Biomedical Research Institute, 4 Dickerson Street, WA 98109 1651, USA.

The EMBL accession numbers for the nucleotide sequence data reported in this paper are X76255-X76258.
}

There is a broad correlation between the rate of growth of a bacterium and the number of ribosomes it produces (Bremer \& Dennis, 1987; Winder \& Rooney, 1970). The number of ribosomes is determined by the production of rRNA, which in turn depends on the number of rRNA $(r r n)$ operons, the strength of their promoters and the efficiency with which the operons are transcribed.

It has already been demonstrated that fast-growing mycobacteria such as Mycobacterium phlei and Mycobacterium smegmatis have two rrn operons (Bercovier et al., 1986; see also Cox \& Katoch, 1986) while slowgrowers have a single $r r n$ operon (Bercovier et al., 1986). The single $r r n$ operon of the slow-growers has a classical structure (Liesack et al., 1990, 1991; Sela \& Clark-Curtiss, 1991; Suzuki et al., 1988; Kempsell et al., 1992), shown in Fig. 1. The operon is transcribed as a single unit (precursor- or pre-rRNA) which is cleaved by RNases to precursors of $16 \mathrm{~S}$ rRNA (pre-16S rRNA), 23S rRNA 
(pre-23S rRNA) and 5S rRNA (pre-5S-rRNA). Mature rRNA species are derived from the precursors by further RNase treatment.

We have previously characterized the promoter, processing sites and antitermination elements of the rrn operon of slow-growers (Kempsell et al., 1992; Ji et al., 1994a, b). In order to gain further understanding of how the slow-growing and fast-growing species control ribosome synthesis we have now further characterized the two $r r n$ operons of the fast-grower $M$. smegmatis.

\section{METHODS}

Materials. Restriction endonucleases were from Boehringer Mannheim, and AMV reverse transcriptase from Life Technologies. Polynucleotide kinase and $\mathrm{T}_{4}$ ligase were supplied by Pharmacia. Sequenase (USB) sequencing kit was from Cambridge Biosciences. $\left[{ }^{35}\right.$ S]dATP- $\alpha S$ and $\left[{ }^{32}\right.$ P]ATP were from Amersham. Geneclean kit was from Bio101. AmpliTaq DNA polymerase was supplied by Perkin Elmer Cetus. Oligonucleotide primers were prepared with an automated DNA synthesizer: (model 370A, Applied Biosystems).

Bacterial strains and vectors. Mycobacterium phlei NCTC 8151 , M. smegmatis NCTC 8159 (National Collection of Type Cultures) and $M$. smegmatis $\mathrm{mc}^{2} 155$ (a generous gift from W. Jacobs, Albert Einstein College of Medicine, New York, USA; see Snapper et al., 1990) were maintained on slopes of LowensteinJensen medium and stored at room temperature. pBluescript (pKS) vector (Stratagene) was used for cloning mycobacterial DNA; the host was Eschericbia coli strain $\mathrm{DH} 5 \alpha \mathrm{F}^{\prime}$. The shuttle vector $\mathrm{pEJ} 106$ was given by $\mathrm{Dr}$ E. Davis, National Institute for Medical Research, Mill Hill, London; it was used to clone mycobacterial DNA first into E. coli and then into $M$. smegmatis $\mathrm{mc}^{2} 155$.

Media. $M$. phlei and $M$. smegmatis were grown overnight at $37^{\circ} \mathrm{C}$ in $5 \mathrm{ml}$ Lemco broth containing $0.05 \%$ Tween 80 . This culture was used to inoculate $200 \mathrm{ml}$ of the Lemco Tween 80 medium. Large cultures were incubated at $37^{\circ} \mathrm{C}$ with rotary shaking (150 r.p.m.; model G25 Shaking Incubator, New Brunswick Scientific). M. smegmatis for electroporation was grown in modified Dubos liquid medium (Dubos \& Davis, 1946) for $24 \mathrm{~h}$, as described above. After electroporation $M$. smegmatis was plated on Middlebrook $7 \mathrm{H} 10$ agar (Difco) containing $10 \%(\mathrm{v} / \mathrm{v})$ Dubos medium albumin supplement (Difco) and 10-15 $\mu \mathrm{g}$ kanamycin $\mathrm{ml}^{-1}$. Purity of cultures was checked using acid-fast staining.

E. coli was grown in Luria-Bertani (LB) or $2 \times$ TY medium, with antibiotics added as required (Sambrook et al., 1989). Cultures were incubated at $37^{\circ} \mathrm{C}(200-330$ r.p.m.) for $18-24$ h.

Construction of plasmid pJY104. The $1.2 \mathrm{kbp} P_{s t} \mathrm{I}$ fragment of the $r r n$ operon of $M$. tuberculosis, which contains nearly 650 bp of $16 \mathrm{~S}$ rRNA gene coding region and $550 \mathrm{bp}$ of its $5^{\prime}$-end flanking region, was introduced into the multiple cloning site of the

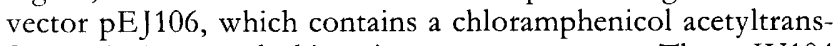
ferase (cat) gene lacking its own promoter. The pJY104 construct contains the promoter in the correct orientation for the expression of the cat gene (Ji tt al., 1994a). The construct was used to transform both $E$. coli $\mathrm{DH} 5 \alpha \mathrm{F}^{\prime}$ and $M$. smegmatis $\mathrm{mc}^{2}$ 155. After transformation, the rRNA was isolated.

Transformation of $\boldsymbol{M}$. smegmatis by electroporation. Electroporation of mycobacteria was carried out using an adaptation of the method described by Snapper et al. (1990). One millilitre of an overnight culture of M. smegmatis $\mathrm{mc}^{2} 155$ was used to inoculate $100 \mathrm{ml}$ modified Dubos medium and the culture was grown at $37^{\circ} \mathrm{C}$ for $24 \mathrm{~h}$. The cells were harvested by centrifugation ( $220 \mathrm{~g}$ for $10 \mathrm{~min}$ ), washed in $10 \%(\mathrm{v} / \mathrm{v})$ glycerol and resuspended in $10 \mathrm{ml} 10 \%(\mathrm{v} / \mathrm{v})$ glycerol.

Plasmid DNA, up to $1 \mu \mathrm{g}$, was added to $0.8 \mathrm{ml}$ of the cell suspension and placed in an electroporation cuvette $(0.2 \mathrm{~cm}$ electrode gap) on ice for $10 \mathrm{~min}$. The cells were then given a single pulse of $25 \mu \mathrm{F}$ at $6250 \mathrm{~V} \mathrm{~cm}^{-1}$ with resistance set at ' $\alpha$ ' (Gene Pulser Apparatus, Bio-Rad) and replaced on ice for $10 \mathrm{~min}$. An equal volume of Lemco broth was added and the cells incubated at $37^{\circ} \mathrm{C}$ for $2 \mathrm{~h}$. Cells were pelleted in a microcentrifuge at 1300 r.p.m. for $5 \mathrm{~min}$, resuspended in $100 \mu \mathrm{l}$ Lemco broth and plated on $7 \mathrm{H} 10$ agar plates containing $15 \mu \mathrm{g}$ kanamycin $\mathrm{ml}^{-1}$.

Isolation of DNA. Plasmid DNA was isolated by standard methods exactly as described previously (Ji et al., 1994a). Genomic DNA was isolated from mycobacteria by the method of Katoch \& Cox (1986), avoiding the use of the French pressure cell (see Ji et al., 1994a). RNA was hydrolysed by incubation with 20000 units of RNase T1 (Life Technologies) overnight at $37^{\circ} \mathrm{C}$ in TE buffer. The RNase was removed by phenol/chloroform extractions and the DNA was then ethanolprecipitated (using 0.1 vol. $3 \mathrm{M}$ sodium acetate and 2 vols ethanol) and finally dissolved in $100 \mu \mathrm{l}$ TE buffer. The yield was $2.7 \mathrm{mg}$ DNA from $7.2 \mathrm{~g}$ (wet weight) of $M$. smegmatis.

Isolation of RNA. $M$. smegmatis NCTC 8159 or $\mathrm{mc}^{2} 155$ was harvested by centrifugation, resuspended in lysis buffer and passed through a French pressure cell at 18000 p.s.i. (124 MPa) at $-10^{\circ} \mathrm{C}$ (see Katoch \& Cox, 1986). Insoluble debris was removed by centrifugation at $5000 \mathrm{~g}$ for $10 \mathrm{~min}$ and the supernatant was deproteinized by repeated extraction with chloroform/3-methyl-1-butanol $(24: 1, \mathrm{v} / \mathrm{v})$. RNA was precipitated by the dropwise addition of $0.5 \mathrm{vol}$. ethanol.

Primer extension. The oligonucleotide primers 5 '-CAC ACT ATT GAG TTC TC-3', which is complementary to positions 46-62 (see Fig. 2) of the leader region, and 5'-CTG AGC CAG GAT CAA ACT CTCC-3', complementary to positions 208229 (Fig. 2) (positions 6-27 of the $16 \mathrm{~S}$ rRNA coding region) were end-labelled with ${ }^{32} \mathrm{P}$ by means of $\mathrm{T} 4$ polynucleotide kinase, then gel-purified and dissolved in double-distilled water. The ${ }^{32} \mathrm{P}$-labelled primer $(10 \mathrm{ng})$ was added to $7 \mu \mathrm{l}$ water containing 10-30 $\mu \mathrm{g}$ total RNA. The mixture was denatured at $97^{\circ} \mathrm{C}$ for $10 \mathrm{~min}$ and $2 \mu \mathrm{l}$ of $2 \times$ annealing buffer $(50 \mathrm{mM}$ PIPES $\mathrm{pH} 6.4,2 \mathrm{M} \mathrm{NaCl}$ ) was added. The nucleic acids were annealed at $52{ }^{\circ} \mathrm{C}$ for $20 \mathrm{~min}$, then $90 \mu \mathrm{l}$ reverse transcriptase buffer $(60 \mathrm{mM} \mathrm{NaCl}, 10 \mathrm{mM} \mathrm{NaCl}, 10 \mathrm{mM}$ Tris/HCl pH 8.3, $10 \mathrm{mM}$ DTT, $8 \mathrm{mM} \mathrm{MgCl}, 1 \mathrm{mM}$ each of dCTP, dGTP, dATP and $\mathrm{dTTP}$, and $50 \mu \mathrm{g}$ actinomycin $\mathrm{D} \mathrm{ml}^{-\mathbf{1}}$ ) containing 100 units $\mathrm{ml}^{-1}$ avian myeloblastosis virus (AMV) reverse transcriptase was added to each reaction. The reaction mixture was incubated at $42{ }^{\circ} \mathrm{C}$ for $1 \mathrm{~h}$, extracted twice with phenol/chloroform, ethanol-precipitated, and washed twice with $70 \%(\mathrm{v} / \mathrm{v})$ ethanol. The extension products were separated on a $12 \%(\mathrm{w} / \mathrm{v})$ polyacrylamide-urea gel and visualized by autoradiography.

DNA polymerase chain reaction (PCR). Bacterial DNA (1 $100 \mathrm{ng}$ ) was subjected to PCR in a total volume of $50 \mu \mathrm{l}$, with 1 unit Taq polymerase, $50 \mathrm{mM} \mathrm{KCl}, 10 \mathrm{mM}$ Tris $/ \mathrm{HCl} \mathrm{pH} 8 \cdot 3$, $1.5 \mathrm{mM} \mathrm{MgCl}, 0.01 \%$ gelatin, $100 \mathrm{pmol}$ of each of two appropriate primers and $200 \mu \mathrm{M}$ each of dATP, dCTP, dGTP and dTTP. The $50 \mu \mathrm{l}$ mixture was covered by $50 \mu \mathrm{l}$ of light mineral oil. The relevant gene fragment coding for the leader region was synthesized using primer combination 1 (primer L1 $5^{\prime}$-GGG TTG CCC CGA AGC G-3' $3^{\prime}$; and $\operatorname{cg} 85^{\prime}$-CAC TGC TGC CTC CCG TAG G-3'; see Ji et al., 1994b) Spacer-1 was amplified using primer combination 2 (g5 5'-GCC AAG GCA TCC ACC ATG C-3'; and cg10 5'-ATT GAC GGG GGC CCG CAC AAG $C G-3^{\prime}$ ) as described by Ji et al. (1994b); and the gene 
fragment coding for spacer-2 was amplified using primer combination 3 (S2-1, 5'-CCA GTT CTC TCA CCA GGG G-3'; and $\mathrm{S} 2-2,5^{\prime}$-CAC ACA CAT CGC AAC CAC-3'). The target for primer S2-1 is a sequence located approximately $210 \mathrm{bp}$ upstream from the 3 '-end of the $23 \mathrm{~S}$ rRNA gene of $M$. leprae (positions 3224-3242, EMBL Data Library Accession Number X56657; Liesack et al., 1991). The target for primer S2-2 is positions 42-59 of the 5S rRNA gene (see Dams et al., 1987). Amplification was achieved using 36 cycles. The reaction mixture was heated to $90^{\circ} \mathrm{C}$ for $1 \mathrm{~min}$, kept at $58^{\circ} \mathrm{C}$ for $1 \mathrm{~min}$, then heated to $70{ }^{\circ} \mathrm{C}$ for $2.5 \mathrm{~min}$, and this cycle was repeated 35 more times. Finally, the solution was heated to $94^{\circ} \mathrm{C}$ for $15 \mathrm{~s}$, then kept at $58{ }^{\circ} \mathrm{C}$ for $1 \mathrm{~min}$ and at $72{ }^{\circ} \mathrm{C}$ for $5 \mathrm{~min}$.

Inverse PCR (Triglia et al., 1988). Genomic DNA of $M$. smegmatis NCTC 8159 was digested with $\mathrm{Bam} \mathrm{HI}$ for $2 \mathrm{~h}$ at $37^{\circ} \mathrm{C}$. Circularization was performed in the same tube with T4 DNA ligase in a low DNA concentration $\left(5 \mu \mathrm{g} \mathrm{ml}^{-1}\right)$ that favours the formation of monomeric circles. Ligase activity was destroyed by heating to $68^{\circ} \mathrm{C}$ for $15 \mathrm{~min}$. After phenol-extraction and ethanol-precipitation, the digested and circularized DNA was resuspended in $10 \mu \mathrm{l}$ water. Two primers [5'-GTG CCA GCA GCC GCG GTA ATA CG-3', identical to the M. tuberculosis $16 \mathrm{~S}$ rRNA gene sequence at positions 1126-1148 (Kempsell et al., 1992); and cg8, 5'-CAC TGC TGC CTC CCG TAG GAG T-3', complementary to the $M$. tuberculosis $16 \mathrm{~S}$ rRNA gene sequence at positions 960-978] were used with their $3^{\prime}$-end facing the unknown region. The other conditions were the same as for normal PCR.

PCR cloning. The methods described by Ji et al. (1994b) were used. The products of PCR were separated by agarose gel electrophoresis. DNA was recovered from the gel by using glass milk (Vogelstein \& Gillespie, 1979). Bluescript phagemid was digested with EcoRV and modified by the addition of a single thymidine at the $3^{\prime}$-ends to facilitate the ligation with PCR products which are found to have an overhanging adenosine residue at the $3^{\prime}$-end (Clark, 1988). The ratio of vector to insert was kept $1: 1$.

Sequencing of double-stranded DNA. At least five colonies from the same ligation reaction were selected, cultured and plasmid DNA isolated. Sequences of the inserted DNAs were determined. This procedure reduces the possible errors caused by PCR amplification (Saiki et al., 1988). DNA sequences were determined by the dideoxy chain-termination procedure using $\left[{ }^{35} \mathrm{~S}\right] \mathrm{dATP}-\alpha \mathrm{S}$, as described by Ji et al. (1994a).

\section{RESULTS}

The scope of this study and the strategies employed are described in Fig. 1. Nucleotide sequence data were obtained for the leader regions of the $\operatorname{rrn} A$ and $r r n B$ operons of $M$. smegmatis and for the spacer- 1 and spacer2 regions of the two operons. The sequence data are summarized in Fig. 2. Nucleotide positions are numbered from the $5^{\prime}$-end of the section of the leader region established for $r r n A$. The sizes of the regions which were studied are given in Table 1 . The three antitermination elements, Box A, Box B and Box C, found in the leader and spacer-1 regions (Berg et al., 1989), are distinguished by the subscripts $L$ (for leader) and $S$ (for spacer- 1 ).

\section{The leader region}

The $r$ rnA operon. Previously we identified a putative Box $B_{L}$ antitermination element near to the site for the start of transcription of the rrn operon of $M$. tuberculosis (Kempsell et al., 1992). Later, an identical or very similar sequence was detected in all eight of the slow-growers studied (Ji $e t$ al., 1994a). Genomic DNA was amplified by using one primer (L1) directed at the putative Box $\mathrm{B}_{\mathrm{L}}$ element and another $(\operatorname{cg} 8)$ directed at a highly conserved sequence of the $16 \mathrm{~S}$ rRNA coding region. The products ranged in size from 539 to $563 \mathrm{bp}$, and comprised 183-207 bp of 5'flanking sequence and approximately $365 \mathrm{bp}$ of the $16 \mathrm{~S}$ rRNA gene (Ji et al., 1994a). The same two primers generated a product of 559 bp when genomic DNA of $M$. smegmatis was the substrate for the PCR reaction. The product was cloned and sequenced (see Fig. 2). On the basis of the assumption that the $5^{\prime}$-end of $16 \mathrm{~S}$ rRNA is pUUG (see Fig. 2) the product comprised $202 \mathrm{bp}$ of $5^{\prime}$ flanking sequence and $357 \mathrm{bp}$ of the $16 \mathrm{~S}$ rRNA coding region.

The part of the genome which was amplified by the above-mentioned procedure was found to be located within the $1.4 \mathrm{kbp}$ PstI fragment of the $\operatorname{rrn} A$ operon (see Fig. 1). Genomic DNA was restricted with PstI, the products were separated according to size by $1 \%(\mathrm{w} / \mathrm{v})$ agarose gel electrophoresis and DNA was recovered from the gel. The pool of DNA fragments of $1.1-1.7 \mathrm{kbp}$ containing the $1.4 \mathrm{kbp}$ fragment of the $\operatorname{rrn} A$ operon yielded a product with primers $\mathrm{L} 1$ and $\operatorname{cg} 8$ by PCR whereas the $2 \cdot 7-3.7 \mathrm{kbp}$ fraction containing the $3.2 \mathrm{kbp}$ fragment of the $r r n B$ operon did not (results not shown). We infer that $r r n A$ has a motif very similar to the Box $\mathrm{B}_{\mathrm{L}}$ antitermination element found in all the slow-growers studied (Ji et al., 1994a) and that this motif is absent from $r r n B$.

The $r$ rn $B$ operon. The region upstream from the $5^{\prime}$-end of the $16 \mathrm{~S}$ rRNA coding region of the $\mathrm{rrnB}$ operon was investigated by means of the inverse PCR procedure (see Fig. 1 and Methods). The product of 925 bp which was obtained after the final step of amplification by PCR was cloned and sequenced (see Methods). It was found to comprise $334 \mathrm{bp}$ of the $16 \mathrm{~S}$ rRNA gene (positions 695-1028, Fig. 2; positions 493-826 of the coding region), followed by 234 bp of the leader region (positions - 31 to 202), followed by $357 \mathrm{bp}$ of $16 \mathrm{~S}$ rRNA gene (positions 203-559; positions $1-357$ of the coding region). The results (Fig. 2) confirm the absence from $r r n B$ of the Box $\mathrm{B}_{\mathrm{L}}$ motif found in slow-growers. However, downstream from position 33 (Fig. 2) the sequences of $r r n A$ and $r r n B$ were identical.

\section{The start of transcription}

The target for the ${ }^{32} \mathrm{P}$-labelled primer used to investigate the start of transcription was the sequence 46-62 (Fig. 2) which is present in the leader regions of $r r n A$ and $r r n B$ and also the $r r n$ operons of slow-growers.

When the RNA fraction of $M$. smegmatis was investigated by the primer extension method, the principal product was DNA of approximately 230 nucleotides (nt), with minor products of approximately $135 \mathrm{nt}$ and approximately $162 \mathrm{nt}$, which could be the result of RNase cleavage of the major product. Thus, the start of transcription of 
(a)
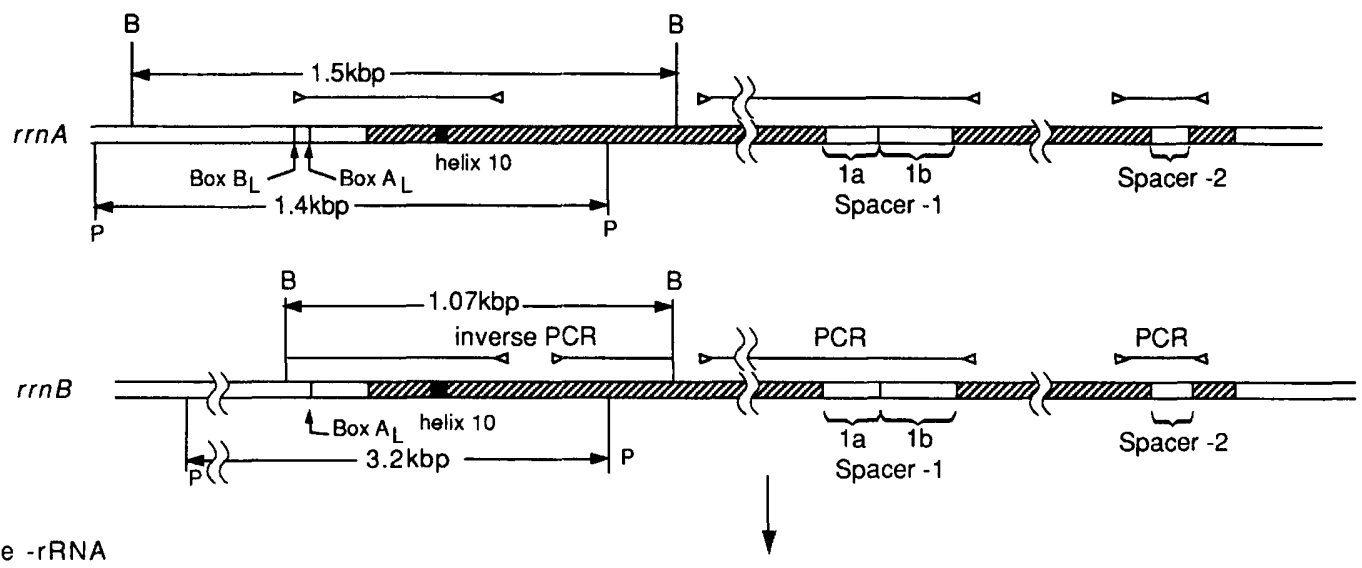

(b) pre -rRNA

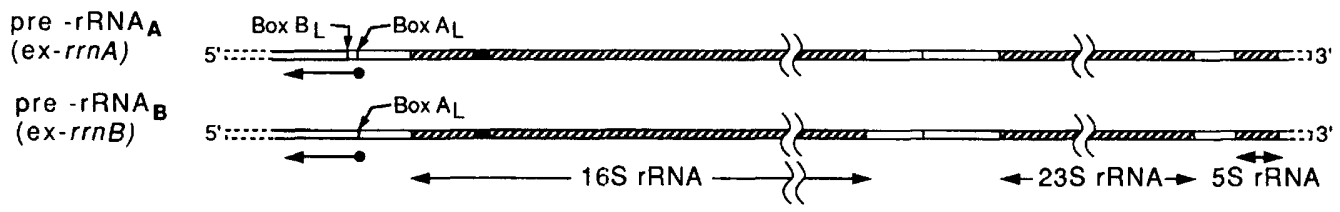

(c)

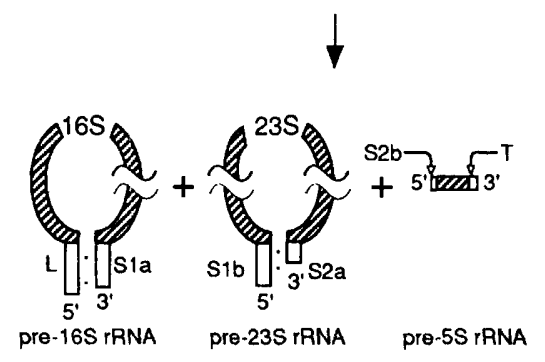

Scale : 200 base pairs or nucleotides

Fig. 1. Strategies used in this investigation. (a) $r$ rn operons of $M$. smegmatis. The BamHI (B) and Pstl (P) sites serve to distinguish $r n n A$ from $r n B$ (Bercovier et al., 1989). The same primers which amplify the leader region of slow growers (Ji et al., 1994a) also amplify part of the leader region of $r r n A$ but not $r r n B$. This reveals the presence of a slow-grower-like Box $B$ antitermination element in $r r n A$ and its absence from $r r n B$. Part of the leader region of $r r n B$ was obtained by first circularizing the BamHI fragment and then amplifying by inverse PCR (Triglia et al., 1988) as described in Methods. The primers used to amplify spacer-1 and spacer-2 amplify both $r$ rnA and $r$ rnB. Amplified DNA was cloned and sequenced (see Methods). Box A and Box B are antitermination elements. Helix 10, which is part of the variable region V2, serves as a signature sequence useful for identifying the species (Ji et al., 1994a). $\triangleright-\triangleleft$, regions of genomic DNA amplified by PCR; the arrowheads indicate the target sites for the primers. (b) Putative transcripts of $r$ rnA and $r$ rnB operons (approx. $5.6 \mathrm{kbp}$ ). The two transcripts differ in nucleotide sequence upstream from the Box $A$ antitermination element. The location of the $5^{\prime}$-end of the transcripts was investigated by the primer extension method using reverse transcriptase. The target for the primer was a sequence spanning the Box A element, as shown. The broken lines denote uncertainties in the locations of the $5^{\prime}$ - and $3^{\prime}$ - ends of the transcripts. circle represents the primer and the arrow denotes the direction of synthesis of the product. (c) Processing of pre-rRNA yielding intermediate products. The interactions between leader and spacer-1a sequences in pre-16S rRNA and between spacer-1b and spacer- 2 in pre-23S rRNA are represented by dots. In (a-c) the hatched bars represent coding regions of the operons and their transcripts.

both $r r n A$ and $r r n B$ is at least $370 \mathrm{bp}$ upstream from the $5^{\prime}$-end of the 16S rRNA gene, and at least $170 \mathrm{nt}$ from the $5^{\prime}$ end of the Box $B_{L}$ element.

To provide a frame of reference, the site for the start of transcription of the $r r n$ operon of $M$. tuberculosis was investigated in $M$. smegmatis transformed with the promoterless plasmid pJY104. A new primer extension product of $56 \mathrm{nt}$ was obtained (see Fig. 3a). A product of identical size was obtained previously when E. coli was transformed with plasmid pJY104 (Ji et al., 1994a). The start of transcription of the $r r n$ operon of $M$. tuberculosis is approximately $200 \mathrm{bp}$ upstream from the $5^{\prime}$-end of the 16S rRNA gene, close to the $5^{\prime}$-end of the Box B element corresponding to position 3 (Fig. 2). In contrast, transcription of the $\operatorname{rrn} A$ and $r r n B$ operons of $M$. smegmatis starts at least $170 \mathrm{bp}$ further upstream (see Fig. 3a and Table 1). Thus, neither $\operatorname{rrn} A$ nor $r r n B$ has a site for the 
(a)

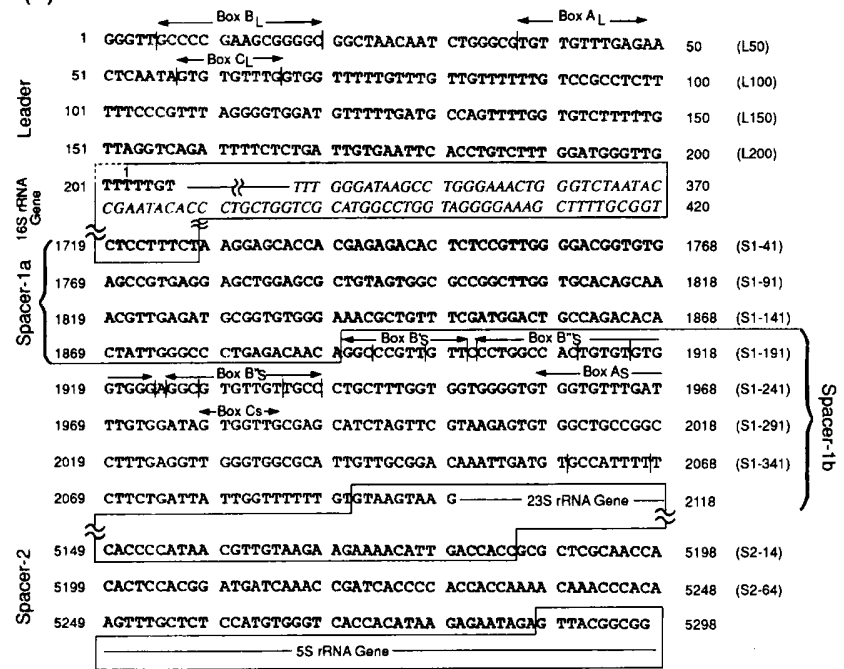

(b)

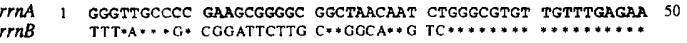

Fig. 2. Nucleotide sequences of part of the leader, the spacer-1 and the spacer-2 regions of the rrnA and $r \mathrm{rnB}$ operons of $M$. smegmatis. (a) Nucleotide sequence of parts of the $r \mathrm{rnA}$ operon, which is identical to the $r$ rnB operon except for nucleotides 1-33, containing Box $B_{L}$. The slow-grower-like Box $B_{1}$ element is present in rrnA but not in $r r n B$. Position 1 was chosen arbitrarily as the $5^{\prime}$-end of primer L1. The partial sequence data obtained for $16 \mathrm{~S}$ rRNA are in agreement with the data of Rogall et al. (1990). The sequence obtained for the variable region $V_{2}$ is given in italics. The sequences of the regions coding for 165 rRNA (1526 bp; see text), 235 rRNA (approx. $3130 \mathrm{bp}$; cf. $23 \mathrm{~S}$ rRNA of $M$. leprae: Liesack et al., 1991) and 5S rRNA are boxed. The $5^{\prime}$-end of $16 \mathrm{~S}$ rRNA and the $5^{\prime}$ - and $3^{\prime}$-ends of 235 rRNA were chosen according to possible processing reactions, but not experimentally determined (see also Fig. 4). Position 1 of the 16S rRNA gene sequence corresponds to position 1 of the $M$. tuberculosis sequence (Kempsell et al., 1992). Putative antitermination elements present in the leader region (Box $A_{L}, B$ Box $B_{L}$ and $B \circ C_{L}$ ) and in the spacer-1 region (Box $A_{s}$, Box $B_{s}^{\prime}$, Box $B_{s}^{\prime \prime}$ and Box $B_{s}^{\prime \prime \prime}$ ) are indicated. (b) Divergence in the nucleotide sequences of the leader regions of the $r r n A$ and $r r n B$ operons upstream from nucleotide position 33. *, nucleotides common to $r$ rnA and $r r n B$.

start of transcription which corresponds to the start site found for $M$. tuberculosis.

\section{RNase cleavage sites}

Pre-16S rRNA is derived from pre-rRNA by the action of RNase III. One cleavage site is located within the leader region (see Fig. 1). This site was identified by means of the primer extension procedures described in Methods. The result shown in Fig. 3(b) was obtained by using a ${ }^{32} \mathrm{P}$ labelled primer complementary to positions $6-27$ of the $16 \mathrm{~S}$ rRNA coding region (positions 208-229, Fig. 2). The principal product was DNA of $177 \mathrm{nt}$, revealing the location of a cleavage site near position 53 . The sequence 49-55 is $5^{\prime}$-AACUCAA-3', which is a homologue of the RNase III cleavage site, $5^{\prime}$-AACUAAA-3', previously (a)

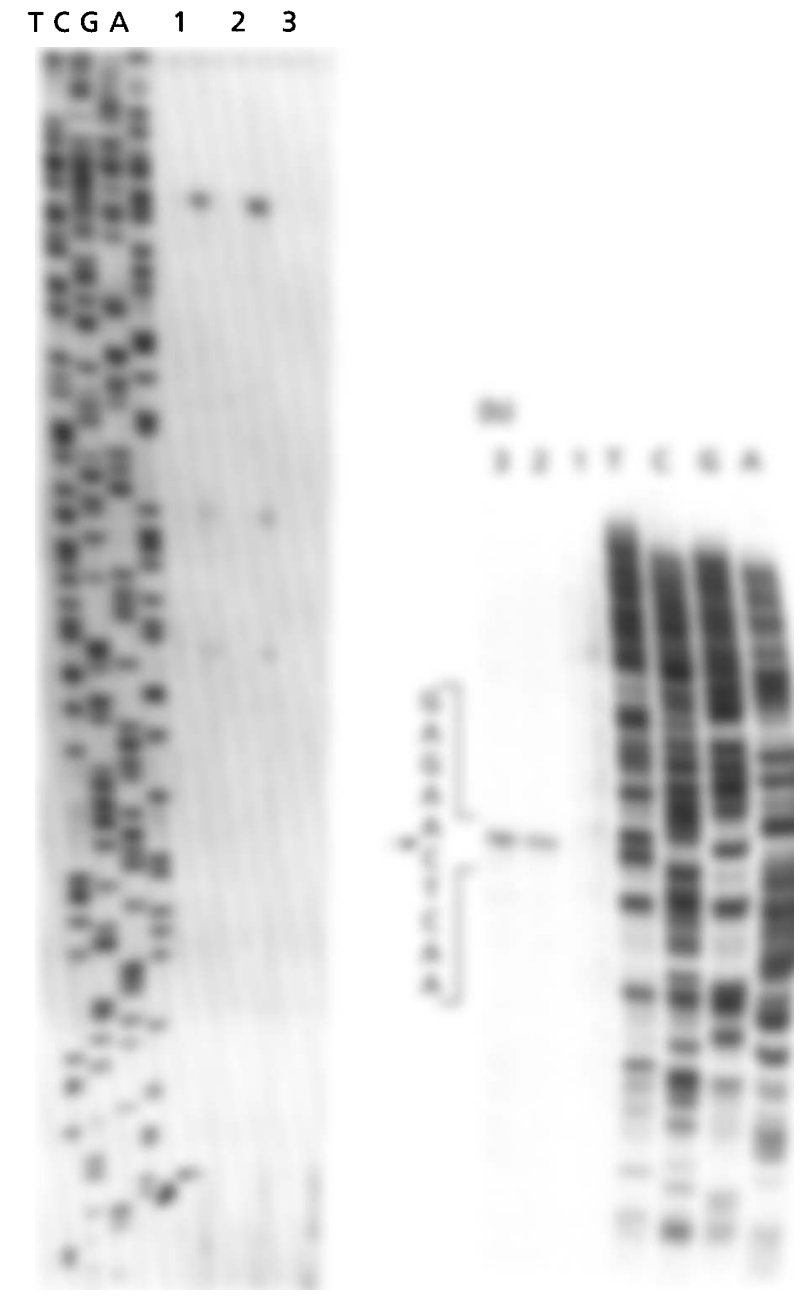

Fig. 3. Comparison of the location of the $5^{\prime}$-ends of pre-rRNAs of $M$. smegmatis and $M$. tuberculosis, and the location of an RNase III cleavage site. (a) The 5 '-ends of $M$. smegmatis prerRNA and $M$. tuberculosis pre-rRNA were located by the primer extension procedure (see Methods), using ${ }^{32} \mathrm{P}$-labelled primer whose target site, residues 46-62 (Fig. 2), is also present in slowgrowers. Lane $1, M$. smegmatis RNA $(12 \mu \mathrm{g})$; lane $2, M$. smegmatis RNA $(24 \mu \mathrm{g})$; lane 3 , no added RNA. Lanes T, C, G and $A$ are sequencing reactions carried out using the same primer as mentioned above and a recombinant phagemid pBluescript II KS(-) containing the sequence, residues 1-559 (Fig. 2), inserted into the ECoRV site. The principal product (lanes 1 and 2) comprised approximately $230 \mathrm{nt}$, suggesting that the start site for transcription is no less than 370 bp from the $5^{\prime}$ end of the 16S rRNA gene. The arrow indicates the location of an extra product (approximately $56 \mathrm{nt}$ ) that was found when $M$. smegmatis was transformed with pJY104. (b) Identification of an RNase cleavage site. ${ }^{32} \mathrm{P}$-labelled primer cg1 (target site, positions 208-229) was used. The sequencing reactions ( $T, C, G$ and $\mathrm{A}$ ) were carried out using primer $\mathrm{cg} 2$ and the recombinant phagemid described in (a). Lane 1 , no added RNA; lane $2, M$. smegmatis RNA $(12 \mu \mathrm{g})$, Lane $3, \mathrm{M}$. smegmatis rRNA $(24 \mu \mathrm{g})$. The sequence of the DNA insert near to the point of cleavage is shown. The major product reveals that the principal cleavage site, marked by the arrow, is located close to position 51 (Fig. $2)$, adjacent to the $3^{\prime}$-end of the Box $A_{L}$ element as illustrated in Fig. 4. 
Table 1. Sizes of the leader, spacer-1 and spacer-2 regions of the $\operatorname{rrnA}$ operon of $M$. smegmatis and comparison with $M$. leprae

Data for M. leprae are from Liesack et al. (1990, 1991), Sela \& Clark-Curtiss (1991) and Kempsell et al. (1992).

\begin{tabular}{|c|c|c|c|c|c|}
\hline \multirow[t]{2}{*}{ Region } & \multicolumn{2}{|c|}{ Size (bp) } & \multirow{2}{*}{$\begin{array}{c}\text { Difference in } \\
\text { size (bp)* } \\
{[M . s m .-M . l e .]}\end{array}$} & \multirow{2}{*}{$\begin{array}{l}\text { Location of } \\
\text { size differences }\end{array}$} & \multirow{2}{*}{$\begin{array}{c}\text { Explanation of size } \\
\text { difference }\end{array}$} \\
\hline & M. sm. & M. le. & & & \\
\hline \multicolumn{6}{|l|}{ Leader } \\
\hline Complete & $\geqslant 370$ & 205 & $\geqslant 165$ & See below & See below \\
\hline $5^{\prime}$-end to $B o x B_{L}$ & $\geqslant 170$ & 4 & $\geqslant 166$ & $\begin{array}{l}\text { Upstream from } \\
\text { Box } B_{L}\end{array}$ & $\begin{array}{l}\text { Difference in the location } \\
\text { of promoters }\end{array}$ \\
\hline Box $B_{L}$ to $3^{\prime}$-end & 200 & 201 & 1 & Not applicable & Not applicable \\
\hline \multicolumn{6}{|l|}{ Spacer-1 } \\
\hline Complete & 362 & 282 & +80 & See below & See below \\
\hline Spacer-1a & 162 & 129 & +33 & $1830-1864$ & Expanded helix S1-4 \\
\hline Spacer-1b & 200 & 153 & +47 & $\begin{array}{l}1912-1933 \\
1998-2069\end{array}$ & $\begin{array}{l}\text { Box } \mathrm{B}_{\mathrm{S}}^{\prime \prime \prime} \text { (extra stem-loop) } \\
\text { Expanded Helix S-5 }\end{array}$ \\
\hline \multicolumn{6}{|l|}{ Spacer-2 } \\
\hline Complete & 102 & 85 & +17 & See below & See below \\
\hline Spacer-2a & 52 & 63 & -11 & $5214-5224$ & Uninterrupted $\mathrm{c}($ stem-S1) \\
\hline Spacer-2b & 50 & 22 & +28 & $5265-5291$ & $\begin{array}{l}\text { Helix S2-2 (extra } \\
\text { stem-loop) }\end{array}$ \\
\hline
\end{tabular}

* The sizes are based on the $5^{\prime}$ - and $3^{\prime}$-ends of $16 \mathrm{~S}$ rRNA and $23 \mathrm{~S}$ rRNA indicated in Fig. 4 and in Ji et al. $(1994 \mathrm{a}, \mathrm{b})$.

identified in the leader region of the $r r n O$ operon of Bacillus subtilis (Ogaswara et al., 1983).

A putative RNase III site was identified in spacer- $1 \mathrm{~b}$ [approximate position 1971 (S1-244), Fig. 2] on the basis of sequence similarities with known sites (cf. Ji et al., 1994b).

\section{The 16S rRNA coding region}

Several parts of the $16 \mathrm{~S}$ rRNA gene were amplified by PCR, cloned and sequenced. Two 5 '-fragments (positions 1-357 of the mature 16S rRNA sequence) were derived independently from $r r n A$ and $r r n B$. The same nucleotide sequence was obtained for each fragment. Part of this sequence, the variable region V2 (positions 138-220 of the $16 \mathrm{~S}$ rRNA gene), is presented in Fig. 2. This region, especially helix 10 , is a valuable guide to the identity of a particular species.

The two other parts of the 16S rRNA gene investigated were positions 493-832 of the $r r n B$ operon and positions 899-1526 of $r r n A$ and $r r n B$. Partial sequences were obtained and were compared with the data of Rogall $\mathrm{et}$ al. (1990) for positions $40-1493$ of the 16S rRNA gene (EMBL Data Bank accession number X52927). Where comparison is possible the two sets of data are in agreement.

The combined data of Rogall et al. (1990) and ourselves suggest an overall length of $1526 \mathrm{nt}$ for the $16 \mathrm{~S} \mathrm{rRNA}$ gene on the basis of the assumption that the $5^{\prime}$-end is pTTTG (see Fig. 2). The $5^{\prime}$-end of M. smegmatis $16 \mathrm{~S}$
rRNA was not identified directly and the number of T residues at the $5^{\prime}$-end is in the range 3-5 (cf. the $5^{\prime}$-end of slow-growers; Ji et al., 1994a). The assignment of position 4 to the first $G$ residue of the $16 S$ rRNA sequence facilitates comparison with the $M$. tuberculosis $16 \mathrm{~S}$ rRNA gene sequence (Kempsell et al., 1992).

\section{The spacer-1 and spacer-2 regions}

$r r n A$ and $r r n B$ have the same overall structure (see Fig. 1) as judged by restriction mapping (Bercovier et al., 1989). The binding sites of the primers used to amplify the spacer- 1 and spacer- 2 regions are highly conserved sequences of the 16S rRNA, 23S rRNA and 5S rRNA genes. Thus the $r r n A$ and $r r n B$ operons should have identical targets for the primers and should be amplified in equal proportions, and clones of $\operatorname{rrn} A$ and $\operatorname{rrnB}$ sequences should be equally abundant. All the clones examined yielded the same spacer- 1 or spacer- 2 sequence. We infer that the nucleotide sequences of the spacer- 1 and spacer2 regions of $r r n A$ and $r r n B$ are identical. The sequences of the $3^{\prime}$-end of the $16 \mathrm{~S}$ rRNA gene, the spacer- 1 region, the $5^{\prime}$ - and $3^{\prime}$ - ends of the $23 \mathrm{~S}$ rRNA gene, spacer- 2 and the $5^{\prime}$ end of the 5S rRNA gene are given in Fig. 2. The sizes of the spacer- 1 and spacer- 2 regions are summarized in Table 1.

\section{Secondary structure of the $r$ rnA operon}

The leader, spacer- 1 , spacer- 2 and trailer regions play a crucial role in determining the three-dimensional structure of pre-rRNA, from which the mature rRNA species 

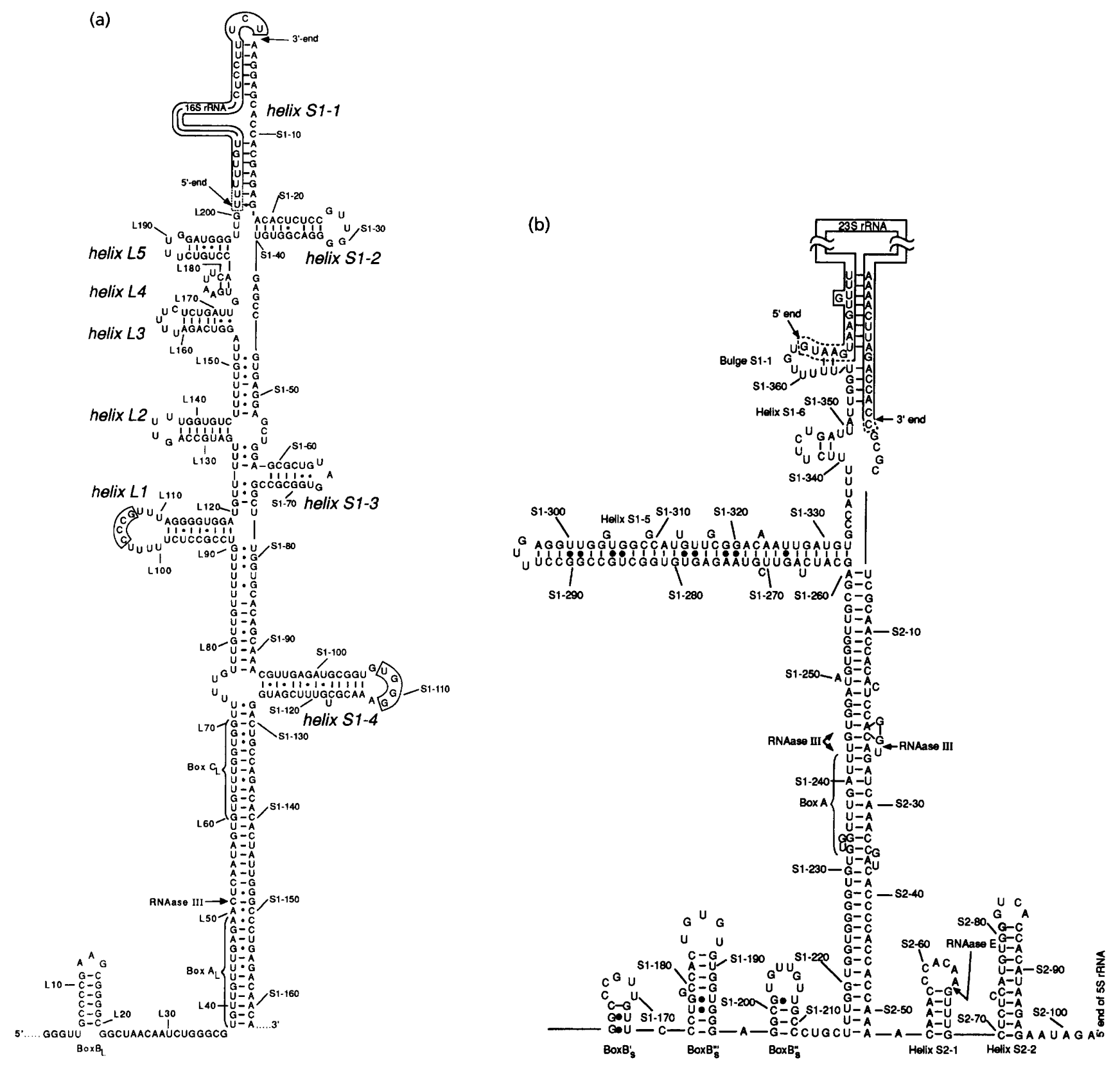

Fig. 4. Schemes for the secondary structure of part of the transcript (pre-rRNA $A_{A}$ of the rrnA operon of $M$. smegmatis. (a) Scheme for the section (see Fig. 2) extending from the $5^{\prime}$-end of primer $L 1$ to the $3^{\prime}$-end of spacer-1A (nucleotides 1-1889). the $5^{\prime}$-end of the transcript is at least 170 nucleotides upstream from the putative Box $B_{b}$ antitermination element. (b) Scheme for the section extending from the 5 '-end of spacer-1b to the 5 '-end of mature $5 \mathrm{~S}$ rRNA (nucleotides 1890-5307). The scheme, which is supported by the extensive sequence similarities, was first proposed for pre-rRNAs of slow-growing mycobacteria ( $\mathrm{Ji}$ et al., 1994a, b). Pre-rRNA $\mathrm{A}_{\mathrm{A}}$ and pre-rRNA $\mathrm{B}_{\mathrm{B}}$ (the transcript of the $r$ rnB operon) are believed to be identical downstream from nucleotide 33 (L33), as shown in Fig. 2. Mature 16S rRNA, 235 rRNA and 55 rRNA sequences are boxed. The broken lines indicate uncertainty in the locations of the $5^{\prime}$ - and $3^{\prime}$-ends of 16S rRNA and $23 S$ rRNA, the approximate locations of which are shown by labelled arrows. Part of the loop of helix L1 and of helix $\$ 4$ is boxed to indicate a possible interaction between the two motifs in the tertiary structure. The capacity of the $5^{\prime}$-terminal sequence of spacer-1 to interact with both the $5^{\prime}$ - and $3^{\prime}$-ends of $16 \mathrm{~S}$ rRNA is illustrated (see helix S1-1). The potential RNase III cleavage site, position L51, was identified by primer extension (see Fig. 3b). The putative RNase site near S1-244 and the putative RNase E site near S2-64 were identified by means of sequence similarities (Régnier \& Hajnsdorf, 1991). A-U, G-C indicate standard 'Watson and Crick' base-pairs; G.U, etc., indicate possible 'wobble' base-pairs.

are derived by the action of RNases. Previously, a scheme of secondary structure for pre-rRNA was proposed which accommodates the nucleotide sequences of $M$. leprae, $M$. tuberculosis and all six other slow-growers studied (Ji et al., 1994a, b). This same scheme of secondary structure applies to the $\operatorname{rrn} A$ operon of M. smegmatis. All the main 


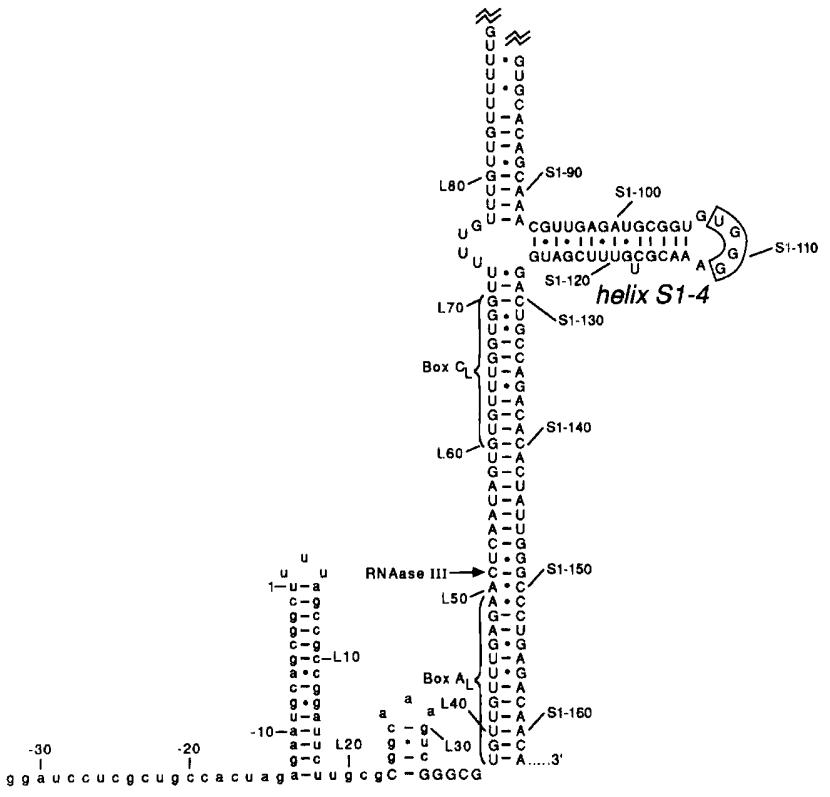

Fig. 5. Possible secondary structure of part of pre-rRNA $A_{B}$. PrerRNA $_{B}$ differs from pre-rRNA $A_{A}$ in the nucleotide sequence upstream from position 33 of rrnA (see Fig. 2), as shown by the lower-case letters. Downstream from position 33 both transcripts appear identical in sequence (upper-case letters) and also in secondary structure.

features described for the secondary structure of slowgrowers are also found in the $\operatorname{rrn} A$ operon. However, there are differences in detail which are described in Table 1. In the pre-16S rRNA moiety the principal difference lies in the location and size of helix S1-4. In slow-growers this helix is located within approximately 5 base-pairs of helix $\mathrm{L} 1$ and comprises approximately 2 base-pairs. In contrast, helix S1-4 of the rrnA operon is more distant (15 basepairs) from helix L1 and is stabilized by approximately 14 base-pairs, although four of them are $\mathrm{G}-\mathrm{U}$ wobble basepairs.

The slow-growers have two Box $\mathrm{B}_{\mathrm{S}}$ stem-loop structures at the $5^{\prime}$-end of spacer- $1 \mathrm{~b}$. In contrast, a third potential Box B-like motif (Box $\mathrm{B}_{\mathrm{S}}^{\prime \prime \prime}$ ) is present in the $\operatorname{rrn} A$ operon and helix S1-5 is longer than in M. leprae. In pre-23S rRNA the long stem is uninterrupted (see Fig. 4) whereas in slower-growers Helix S2-1 is found near to the putative RNase III cleavage site within the pre-23S rRNA stem.

Lastly, the $r r n A$ operon has an extra potential stem-loop structure located between the potential RNase E cleavage site and the $5^{\prime}$-end of the 5S rRNA gene. As discussed below, these differences are reflected in the size of pre-16S rRNA, pre-23S rRNA and pre-5S rRNA derived from the rrn $A$ operon compared with their counterparts derived from pre-rRNA of slow-growers.

The transcript, pre-rRNA, is first cleaved by RNase III to produce pre-16S rRNA and pre-23S rRNA; and by RNase $E$ to produce pre-5S rRNA. Cleavage at these sites would yield pre-16S rRNA comprising mature $16 \mathrm{~S}$ rRNA extended by approximately 149 nt upstream from the $5^{\prime}$ end and approximately $149 \mathrm{nt}$ downstream from the $3^{\prime}$ - end $\left(5^{\prime}-149\right.$ nt-16S rRNA-149 nt- $\left.3^{\prime}\right)$. Pre-23S rRNA is likely to have the structure $5^{\prime}-118 \mathrm{nt}-23 \mathrm{~S}$ rRNA $-24 \mathrm{nt}-$ $\left.3^{\prime}\right)$. Cleavage at the putative RNase E site (position S2-64) would lead to pre-5S rRNA comprising mature $5 \mathrm{~S}$ rRNA extended by $38 \mathrm{nt}$ upstream from the 5 '-end. The estimated sizes of the $M$. leprae precursors (Ji et al., 1994a, b) are: pre-16S rRNA ( $5^{\prime}-160$ nt-16S rRNA-113 nt- $\left.3^{\prime}\right)$, pre$23 \mathrm{~S}$ rRNA (5'-94 nt-23S rRNA-27 nt- $\left.3^{\prime}\right)$ and pre-5S rRNA $\left(5^{\prime}-11\right.$ nt -5 S rRNA-33 nt-3').

\section{Secondary structure of the $r r n B$ operon}

The nucleotide sequence of the $r r n B$ operon differs from that of the $\operatorname{rrn} A$ upstream from position 33 (Fig. 2). A possible secondary structure of this region of the transcript of the $r r n B$ operon is given in Fig. 5. Downstream from position 33 the secondary structure of pre-rRNA $\mathrm{B}_{\mathrm{B}}$ is probably identical with that of pre-rRNA .

\section{Comparison with other fast-growers}

The notion that the $r r n$ operons of $M$. smegmatis may be representative of fast-growers in general is supported by data obtained for the leader and spacer-1 regions of $M$. phlei. Genomic DNA of $M$. phlei is amplified by primers L1 and cg8 yielding a product of approximately $560 \mathrm{bp}$ (Ji, 1993), which is the same size as the product obtained for M. smegmatis. The inference is that at least one of the $r r n$ operons of $M$. phlei also has a slow-grower-like Box B antitermination element approximately 202 bp upstream from the $5^{\prime}$-end of the $16 \mathrm{~S}$ rRNA gene.

The spacer-1 of $M$. phle $i$ was amplified by PCR (results not shown). It was found to be comparable in size ( $355 \mathrm{bp}$ ) with the M. smegmatis spacer-1 region (362 bp). van der Giessen et al. (1994) have reported the nucleotide sequence of the spacer-1 region of $M$. phlei. The $M$. phlei and $M$. smegmatis sequences are compared in Fig. 6. The high degree of homology between the two species includes the features which distinguish $M$. smegmatis from the slowgrower, namely an enlarged (33 nt) helix S1-4 in spacer-1a (see also Fig. 4a) and an extra stem-loop (32 nt) structure (Box B $\mathrm{B}_{\mathrm{S}}^{\prime \prime \prime}$ ) in spacer-1b.

van der Giessen et al. (1994) also showed that each of the fast-growers Mycobacterium fortuitum and Mycobacterium chelonae has a spacer-1 region which is comparable in size with the spacer-1 region of $M$. smegmatis. Thus the sizes of the spacer-1 regions of the $r r n$ operons of these fastgrowers serve to distinguish them from slow-growers, as illustrated in Table 1.

\section{Comparison with slow-growers}

The rrnA operon. Although the $r r n A$ operon of $M$. smegmatis has distinctive features it is clearly closely related to the single $r r n$ operon of $M$. leprae (see Table 1). There are several regions of the $r r n$ operons of slow-growers which were found to have identical sequences (Ji et al., 1994a, b). The same (or very similar) sequences are also present in the $\operatorname{rrn} A$ operon. The regions of high homology are as follows: $31 \mathrm{bp}$ of the leader region [positions 38--68 (L38-L68); Fig. 2]; the complementary 


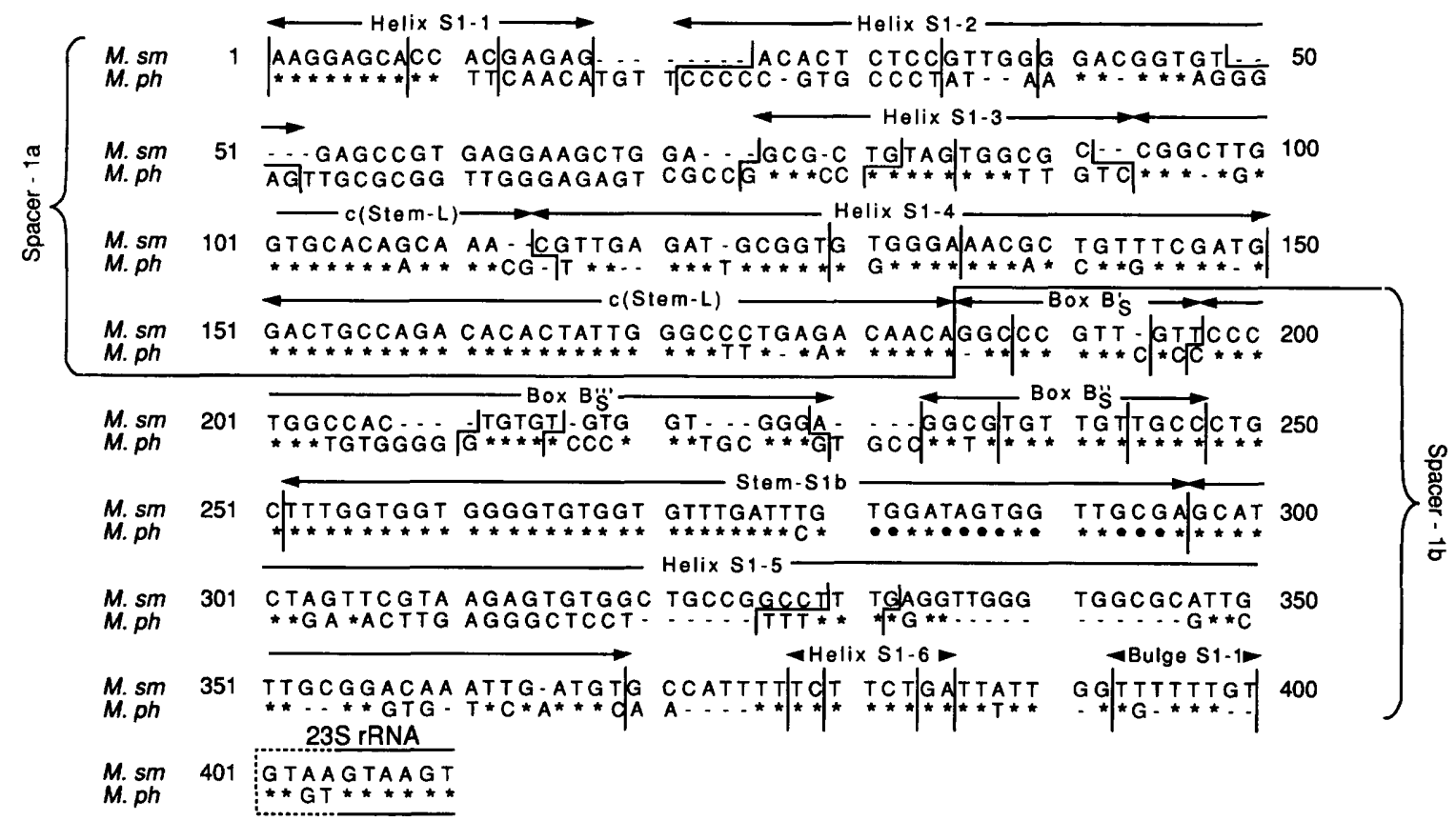

Fig. 6. Comparison of the primary and possible secondary structures of the spacer-1 regions of the $r$ rn operons of $M$. smegmatis (M. sm; see Fig. 2) and $M$. phlei (M. ph; see van der Giessen et al., 1994). Possible features of the secondary structure of the pre-rRNA transcript are indicated by the labelled arrows and short vertical lines, which mark complementary sequences and, where appropriate, the intervening hairpin loop. Stem-loop structures are numbered in sequence (helix S1, etc.) from the $5^{\prime}$-end of spacer- 1 . The sequence designated $c(S t e m-L)$ of the spacer-1a region has the capacity to interact through base-pairing with sequences of the leader region. Similarly, sequences labelled Stem-1b may interact with sequences of spacer-2, as illustrated in Fig. 4(a,b). -, Deletion; *, nucleotide common to $M$. smegmatis and $M$. phlei. 235 rRNA gene sequences are boxed; the broken line denotes uncertainty in the location of the $5^{\prime}$-end.

sequence found in spacer-1a [positions 1859-1889 (S1-132 to S1-162); Fig. 2]; a sequence of $44 \mathrm{bp}$ in spacer-1b [positions 1944-1987 (S1-217 to S1-260); Fig. 2]; and the complementary regions located in spacer-2a [positions 5190-5199 (S2-5 to S2-14) and positions 5223-5237 (S238 to S2-52); Fig. 2]. In addition, there are extensive sequence homologies as shown by the scheme of secondary structure of pre-rRNA (see Fig. 4) and prerRNA of slow-growers (Ji et al., 1994a, b).

Antitermination motifs. Possible antitermination elements present in the non-coding regions of the $\operatorname{rrnA}$ operon of $M$. smegmatis are also present in the $r r n$ operon of $M$. leprae, which is representative of slow-growers (Ji $e t$ al., 1994a, b). Elements identical to Box $B_{L}, B o x A_{L}$ and Box $C_{\mathrm{L}}$ found in M. smegmatis are also present in M. leprae. The Box $\mathrm{B}_{\mathrm{S}}^{\prime}$ and Box $\mathrm{B}_{\mathrm{S}}^{\prime \prime}$ of the $\operatorname{rrn} A$ operon are homologues of their counterparts in $M$. leprae but they are separated by a third stem-loop structure (Box $\mathrm{B}_{\mathrm{S}}^{\prime \prime \prime}$ ); the Box $A_{s}$ element of the $\operatorname{rrn} A$ operon is $5^{\prime}-$ UGGUGUUUGAUU-3' and so differs in one position from Box $A_{\mathrm{S}}$ of $M$. leprae (5'-UGGUGUUUGAGU-3') whereas Box $\mathrm{C}_{\mathrm{S}}$ is identical for both $\operatorname{rrn} A$ and the slowgrower. These similarities suggest that the mechanisms of antitermination, particularly those involving Box $\mathrm{A}$, are very similar for $M$. smegmatis, $M$. leprae and other slowgrowers.

The rrnB operon. The mechanisms of antitermination and of processing by means of RNase cleavages discussed above for the $\operatorname{rrn} A$ operon and its transcript pre-rRNA also apply to the $r r n B$ and its transcript pre-rRNA $\mathrm{B}_{\mathrm{B}}$. The two operons are identical downstream from position 33 and differ in that a slow-grower-like Box $B_{L}$ element is absent from $r r n B$. The significance of this difference remains to be evaluated.

\section{DISCUSSION}

The sequence data obtained for the non-coding regions of the two $r r n$ operons of the representative fast-grower $M$. smegmatis extend our knowledge of $r r n$ operons of mycobacteria. These data, together with previous work (Ji et al., 1994a, b), support two conclusions. First, there are features of the non-coding regions which are characteristic of the genus; these include the highly conserved sequences of the leader, spacer- 1 and space- 2 regions (see above), and the overall scheme of secondary structure proposed for pre-16S rRNA and pre-23S rRNA (see Fig. 4). Secondly, there are clear differences between fastgrowers and slow-growers which are evident in the spacer-1 and spacer-2 (see Table 1).

\section{Box $\mathrm{A}$ antitermination motifs}

The mycobacterial Box $A_{L}$ and Box $A_{S}$ sequences are related to, but different from, the Box $A$ sequences reported for other species (Berg et al., 1989; Ji et al., 
1994a, b). One function of the Box A sequences of prerRNA is to form a complex with transcription factors, in particular with a heterodimer of NusB and S10 or their analogues, which may then attach to the polymerase (Nodwell \& Greenblatt, 1993).

\section{Why does each rrn operon have two Box A elements?}

This question was considered taking into account the proposed secondary structure of pre-rRNA (Fig. 4) and on the basis of the assumption that, as transcription proceeds, the growing pre-rRNA chain folds forming stem-loop structures, etc., to which ribosomal proteins bind in a defined order. The growing transcript of the $16 \mathrm{~S}$ rRNA gene and its associated proteins may be regarded as the precursor of the small (30S) subunit.

We propose that the two Box A elements are needed for the complete transcription of the rrn operon because the copy of the NusB.S10 heterodimer, which attaches to the polymerase at the Box $A_{\mathrm{L}}$ element, is detached from the polymerase at a point where transcription of the $16 \mathrm{~S}$ rRNA gene nears completion and before the $3^{\prime}$-end of spacer-1a is reached. To prevent premature transcription termination of the $23 \mathrm{~S}$ rRNA gene and $5 \mathrm{~S}$ rRNA genes, a second copy of the NusB.S10 heterodimer attaches to the Box $A_{S}$ sequence and stays with the polymerase until transcription of the operon is complete, or at least nears completion.

There are several ways in which the NusB. S10 heterodimer might be displaced from the polymerase. One possibility is based on competition for the Box $A_{L}$ sequence bound to the NusB. S10 heterodimer. Helix S11 (Fig. 4a) brings together the $5^{\prime}$ - and $3^{\prime}$-ends of $16 \mathrm{~S}$ rRNA and so facilitates the formation of the long stem of pre-16S rRNA which is formed through the interaction of stem- $L$ sequences of the leader region with $c($ stem- $L)$ sequences of the spacer-1a region. Box $A_{L}$ is part of the stem- $L$ sequence. Hence, formation of the stem is based on competition between the $c($ stem-L) sequence and the NusB.S10 heterodimer for Box $A_{L}$. As a result of the formation of the stem, the NusB. S10 heterodimer is lost from the polymerase and a second copy attaches to the polymerase at Box $A_{S}$, and remains attached until the formation of the pre-23S rRNA stem. There is no Box A element present in the spacer- 2 region so that the $5 \mathrm{~S}$ rRNA gene would be transcribed in the absence of a NusB. S10 heterodimer as a component of the polymerase.

The nascent ribosomal subunit has the potential to compete with the RNA polymerase for S10. Taking the E. coli ribosome as a model, a single copy of S10 is located within the $3^{\prime}$ major domain of the small subunit, where it is stabilized by interactions with its protein neighbours S3, S9 and S14 and by interaction with 16S rRNA sequences 1130-1280 (Stern et al., 1989). Incorporation of S10 into the small subunit could take place after elongation of the transcript to nucleotide 1390 if, as in the assembly of the subunit in vitro (Nomura, 1973), incorporation of S10 follows the incorporation of protein
S7, which has a complex 16S rRNA binding site (Stern $e t$ al., 1989). Thus, a second possibility is that at a point late in the transcription of $16 \mathrm{~S}$ rRNA gene the nascent small subunit may compete with the RNA polymerase for the copy of $\mathrm{S} 10$ present as a heterodimer with NusB, leading to the transfer of S10 from the polymerase to the nascent subunit. NusB could be said to act as a temporary scaffold or chaperone for S10. The heterodimer which subsequently attaches to RNA polymerase at Box $A_{S}$ will remain attached until transcription is complete.

A third possibility is that both competing reactions are coordinated so that, as $\mathrm{c}(\mathrm{stem}-\mathrm{L}$ ) sequences are synthesized, the copy of $\mathrm{S} 10$ which is released from the polymerase is transferred to the nascent subunit.

We conclude that during the transcription of the $\operatorname{rrn} A$ operon the mycobacterial homologues of NusB and S10 form a heterodimer which attaches to the polymerase at Box $A_{L}$ (nucleotides 38-49, Fig. 2) and remains attached until it is displaced from the polymerase after elongation to nucleotide 1322 and before elongation to nucleotide 1889. A second heterodimer of NusB and S10 attaches at Box $A_{S}$ (nucleotides 1958-1969) and remains attached at least until elongation to nucleotide 5214. Also, we infer that the NusB and S10 homologues of fast- and slowgrowers are very closely related because of the identity of the Box $A_{L}$ sequence and the near identity of the Box $A_{S}$ sequence of species of both divisions of mycobacteria.

\section{A homologue of rrnA is present in slow-growers}

The division into fast-growers and slow-growers is reflected in the phylogeny of mycobacteria inferred from 16S rRNA sequences (see for example Stahl \& Urbance, 1990; Rogall, et al., 1990; Stackebrandt \& Smida, 1988; Pitulle et al., 1992). In summary, 'The fast-growing mycobacteria (ranging from $M$. chelonae subsp. abscessus to $M$. thermo-resistible) and the slow-growing mycobacteria (ranging from $M$. triviale to $M$. paratuberculosis) are phylogenetically separated. The branching point of the rapidly growing members, close to the root of the mycobacterial subline, indicates that these organisms are phylogenetically older than their slow-growing relatives' (Pitulle et al., 1992).

Fast-growers and slow-growers differ in the number of $r r n$ operons per mycobacterium; fast-growers, including $M$. phlei and M. smegmatis have two rrn operons whereas slowgrowers, including $M$. tuberculosis and $M$. leprae, have one operon (Bercovier et al., 1986).

The following tentative hypothesis is based on the assumption that the $r r n$ operons of $M$. smegmatis are representative of fast-growers in general, including the most ancient species. In other words, each fast-growing mycobacterium has two $r r n$ operons, $r r n A_{\mathrm{f}}$ and $r r n B_{\mathrm{f}}$, specific examples of which are $r r n A$ and $r r n B$ of $M$. smegmatis. The characteristic features of $\operatorname{rrn} A_{\mathrm{f}}$ include a binding site for primer L1 approximately 200 bp upstream from the $5^{\prime}$-end of the $16 \mathrm{~S}$ rRNA gene and a spacer- 1 region of approximately $360 \mathrm{bp}$. The single $r r n$ operon of slow-growers is closely related in primary and secondary 
structure to $r r n A_{\mathrm{f}}$, and hence we propose that, at an early stage in the development of the genus, a mycobacterium emerged which had lost a segment of DNA carrying the $r r n B_{\mathrm{f}}$ operon and possibly also other genes. The remaining $r r n A_{\mathrm{f}}$ operon became the precursor of the $r r n A_{\mathrm{S}}$ operon, which is now characteristic of slow-growers, with a leader region of approximately $200 \mathrm{bp}$ and an abbreviated spacer-1 region. Each of the slow-growers we have investigated has an $r r n$ operon of the $r r n A_{\mathrm{S}}$ family (Ji et al., 1994a, b).

The mechanisms by which $M$. smegmatis and other fastgrowing mycobacteria control expression of the two rrn operons is not known. Identification of the promoter elements of the two operons and their contribution to the growth of $M$. smegmatis would be helpful. The significance of the differences observed in the promoter regions of $r n A_{\mathrm{f}}$ operons of fast-growers and the $\operatorname{rrn} A_{\mathrm{S}}$ operon of slow-growers may then become apparent.

Finally, the methods used to amplify the non-coding (leader, spacer-1 and spacer-2) regions of the $r r n$ operons of $M$. smegmatis are likely to be generally applicable and so broaden the scope for devising genus-specific and speciesspecific primers and probes for the identification of mycobacteria.

\section{ACKNOWLEDGEMENTS}

This investigation received support from the UWDP/WHO special programme for Research Training in Tropical Diseases and from the British Leprosy Relief Association (LEPRA). Dr Yuan-en Ji was supported by a grant from LEPRA.

\section{REFERENCES}

Bercovier, H., Kafri, O. \& Sela, S. (1986). Mycobacteria possess a surprisingly small number of ribosomal RNA genes in relation to the size of their genome. Biocbem Biopbys Res Commun 136, 1136-1141.

Bercovier, H., Kafri, O., Kornitzer, D. \& Sela, S. (1989). Cloning and restriction analysis of ribosomal RNA genes from Mycobacterium smegmatis. FEMS Microbiol Lett 57, 125-128.

Berg, K. L., Squires, C. \& Squires, C. L. (1989). Ribosomal RNA operon anti-termination: function of leader and spacer region Box B-Box $A$ sequences and their conservation in diverse microorganisms. J Mol Biol 209, 345-358.

Bremer, H. \& Dennis, P.P. (1987). Modulation of chemical composition and other parameters of the cell growth rate. In Escherichia coli and Salmonella typhimurium: Cellular and Molecular Biology, pp. 1527-1542. Edited by F. C. Neidhardt and others. Washington, DC: American Society for Microbiology.

Clark, J. M. (1988). Novel non-templated nucleotide addition reactions catalyzed by prokaryotic and eukaryotic DNA polymerase. Nucleic Acids Res 16, 9677-9686.

Cox, R. A. \& Katoch, V. (1986). Evidence for genetic divergence in ribosomal RNA genes of mycobacteria. FEBS Lett 195, 194-198.

Dams, E., Yamada, T., De Baene, R., Huysmans, E., Vandenberghe, A. \& De Wachter, R. (1987). Structure of $5 \mathrm{~S} r \mathrm{RNA}$ in actinomycetes and relatives and evolution of eubacteria. $J$ Mol Evol 25, 255-260.

Dubos, R. J. \& Davis, B. D. (1946). Factors affecting the growth of tubercle bacilli in liquid media. $J$ Exp Med 83, 409-423. van der Giessen, J. W. B., Haring, R. M. \& Zeijst, B. A. M. (1994). Comparison of the $23 \mathrm{~S}$ ribosomal RNA genes and the spacer region between the $16 \mathrm{~S}$ and $23 \mathrm{~S}$ rRNA genes of the closely related Mycobacterium avium and Mycobacterium paratuberculosis and the fastgrowing Mycobacterium phlei. Microbiology 140, 1103-1108.

Ji, Y.-E. (1993). Functional elements of the promoter, leader and intergenic regions of ribosomal $\mathrm{R} N A$ operons of mycobacteria. PhD Dissertation, The Open University.

Ji, Y.-E., Colston, M. J. \& Cox, R. A. (1994a). Nucleotide sequence and secondary structures of precursor $16 \mathrm{~S}$ rRNA of slow-growing mycobacteria. Microbiology 140, 123-132.

Ji, Y.-E., Kempsell, K., Colston, M. J. \& Cox, R. A. (1994b). Nucleotide sequences of the spacer-1, spacer-2 and trailer regions of the $r n$ operons and secondary structures of precursor $23 \mathrm{~S}$ rRNAs and precursor $5 \mathrm{~S}$ rRNAs of slow-growing mycobacteria. Microbiology 140, 1763-1773.

Katoch, V. \& Cox, R. A. (1986). Stepwise isolation of RNA and DNA from mycobacteria. Int J Lepr 54, 409-415.

Kempsell, K. E., Ji, Y.-E., Estrada-G, I. C. E., Colston, M. J. \& Cox, R. A. (1992). The nucleotide sequence of the promoter, 16S rRNA and spacer region of the ribosomal RNA operon of Mycobacterium tuberculosis and comparison with Mycobacterium leprae precursor rRNA. J Gen Microbiol 138, 1717-1727.

Liesack, W., Pitulle, C., Sela, S. \& Stackebrandt, E. (1990). Nucleotide sequence of the $16 \mathrm{~S}$ rRNA from Mycobacterium leprae. Nucleic Acids Res 18, 5558.

Liesack, W., Sela, S., Bercovier, H., Pitulle, C. \& Stackebrandt, E. (1991). Complete nucleotide sequence of the Mycobacterium leprae $23 \mathrm{~S}$ and $5 \mathrm{~S}$ rRNA genes plus flanking regions and their potential in designing diagnostic oligonucleotide probes. FEBS Lett 281, 114-118.

Nodwell, J. R. \& Greenblatt, J. (1993). Recognition of Box A antiterminator RNA by the $E$. coli antitermination factors NusB and ribosomal protein S10. Cell 72, 261-268.

Nomura, M. (1973). Assembly of bacterial ribosomes. Science 179, 864893.

Ogasawara, N., Moriya, S. \& Yoshikawa, H. (1983). Structure and organization of rRNA operons in the region of the replication origin of the Bacillus subtilis chromosome. Nucleic Acids Res 11, 6301-6318.

Pitulle, C., Dorsch, M., Kazada, J., Walters, J. \& Stackebrandt, E. (1992). Phylogeny of rapidly growing members of the genus Mycobacterium. Int J Syst Bacteriol 42, 337-343.

Régnier, P. \& Hajnsdorf, E. (1991). Decay of mRNA encoding ribosomal protein S15 of Escherichia coli initiated by an RNAse Edependent endonucleolytic cleavage that removes the $3^{\prime}$ stabilising stem and loop structure. J Mol Biol 217, 283-292.

Rogall, T., Wolters, J., Flohr, T. \& Bottger, E. C. (1990). Towards a phylogeny and definition of species at the molecular level within the genus. Mycobacterium. Int J Syst Bacteriol 40, 323-330.

Saiki, R. K., Gelfand, D. H., Stöffel, S., Sharf, S. J., Higuchi, K., Horn, G. T., Mullis, K. B. \& Erlich, H. A. (1988). Primer-directed enzymatic amplification of DNA with a thermostable DNA polymerase. Science 239, 487-491.

Sambrook, J., Fritsch, E. F. \& Maniatis, T. (1988). Molecular Cloning: a Laboratory Manual, 2nd edn. Cold Spring Harbor, NY: Cold Spring Harbor Laboratory.

Sela, S. \& Clark-Curtiss, J. E. (1991). Cloning and characterization of the Mycobacterium leprae putative ribosomal RNA promoter in Eschericbia coli. Gene 98, 123-127.

Snapper, S. B., Melton, R. E., Mustafa, S., Kieser, T. \& Jacobs, W. R., Jr (1990). Isolation and characterisation of efficient plasmid 
transformation mutants of Mycobacterium smegmatis. Mol Microbiol 4, 1911-1919.

Stackebrandt, E. \& Smida, J. (1988). The phylogeny of the genus Mycobacterium as determined by $16 \mathrm{~S}$ rRNA sequences, and development of DNA-probes. In Biology of Actinomycetes, pp. 244-250. Edited by Y. Okami, T. Beppu \& H. Ogawara. Tokyo: Japan Scientific Societies Press.

Stahl, D. A. \& Urbance, J. W. (1990). The division between fast and slow-growing species corresponds to natural relationships among the mycobacteria. J Bacteriol 172, 116-124.

Stern, S., Powers, T., Changchien, L.-M. \& Noller, H. F. (1989). RNA-protein interactions in $30 \mathrm{~S}$ ribosomal subunits: folding and function of 16S rRNA. Science 244, 785-790.

Suzuki, Y., Nagata, A., Ono, Y. \& Yamada, I. (1988). Complete nucleotide sequence of the 16S rRNA gene of Mycobacterium bovis BCG. J Bacteriol 170, 1631-1636.

Triglia, T., Peterson, M. G. \& Kemp, D. J. (1988). A procedure for in vitro amplification of DNA segments that lie outside the boundaries of known sequences. Nucleic Acids Res 16, 8186.

Vogelstein, B. \& Gillespie, D. (1979). Preparative and analytical purification of DNA from agarose. Proc Natl Acad Sci USA 76, 615-619.

Winder, F. G. \& Rooney, S. A. (1970). Effects of nitrogenous components of the medium on the carbohydrate and nucleic acid content of Mycobacterium tuberculosis BCG. J G Microbiol 63, 29--39.

Received 18 April 1994; revised 8 June 1994; accepted 14 June 1994. 